\title{
A global health perspective on the future of tobacco control
}

Jonathan M Samet, MD, MS.(I)

\author{
Samet JM. Samet JM. \\ A global health perspective \\ on the future of tobacco control. \\ Salud Publica Mex 2012;54:264-269. \\ Una perspectiva de salud global \\ sobre el futuro del control del tabaco. \\ Salud Publica Mex 2012;54:264-269.
}

\begin{abstract}
In this age of globalization, the outcome of tobacco control in one country is connected to events on the global stage. Tobacco control has become an increasingly consolidated global movement, catalyzed by the global tobacco control treaty, the World Health Organization's Framework Convention on Tobacco Control (FCTC) as well as the Bloomberg Initiative. This global collective effort is necessary in the face of an increasingly aggressive tobacco industry that has consolidated into a small number of very large multinational corporations, operating globally to expand their markets. Looming issues for tobacco control include the success with which the FCTC is implemented within individual nations, finding the proper role of harm reduction approaches, and using "lessons learned" from experience in the United States with tobacco product regulation.
\end{abstract}

Key words: tobacco control; global health; FCTC; tobacco product regulation

\section{Resumen}

Con el desarrollo de la globalización, el resultado del control del tabaco en un país está conectado con eventos mundiales. El control del tabaco se ha convertido en un movimiento mundial cada vez más consolidado, catalizado por el Convenio Marco de la Organización Mundial de la Salud para el Control del Tabaco así como de la Iniciativa Bloomberg. Este esfuerzo colectivo global es necesario, ya que la industria del tabaco ha consolidado una serie de grandes corporaciones multinacionales que trabajan globalmente para hacer crecer sus mercados. Algunos problemas pendientes siguen limitando el éxito del control del tabaco. Los problemas incluyen el relativo éxito de cada país al implementar el Convenio Marco, encontrar el papel del enfoque de reducción de daños, y utilizar experiencias y éxitos de los Estados Unidos en la regulación de productos de tabaco.

Palabras clave: control del tabaco; salud global; Convenio Marco; regulación de productos de tabaco
$\mathrm{T}$ aking the long view, remarkable progress has been made in global tobacco control. In the half century since cigarette smoking was first identified as a major cause of disease, the epidemic of smoking and smokingcaused disease is declining in many countries; airplanes are smokefree throughout the world as are workplaces and public places in many cities, states, and nations; and, a global tobacco control treaty, the World Health Organization's Framework Convention on Tobacco Control (FCTC) has been in place for more than five years. ${ }^{1}$

(I) Department of Preventive Medicine, Keck School of Medicine, and Institute for Global Health, University of Southern California. Los Angeles, California, USA.

Received on: March 6, 2012 - Accepted on: March 20, 2012

Corresponding author: Jonathan M. Samet. Department of Preventive Medicine, Keck School of Medicine, and Institute for Global Health, University of Southern California. Los Angeles, California, USA. Institute for Global Health, University of Southern California.

200 I N. Soto Street, Suite 330A Los Angeles, CA 90089-9239 USA.

E-mail: jsamet@med.usc.edu 
$\mathrm{M}$ exico is among the nations that have made great progress. Fortunately, smoking rates have been historically low and smokers in Mexico tend to smoke relatively few cigarettes compared with smokers in other countries; men who are daily smokers average around 10 cigarettes per day and women even less, around 8 per day. ${ }^{2}$ Mexico has moved to implement a national law to make workplaces and public places smokefree and a law is already in place in the Distrito Federal. However, Mexico, like other nations, faces the challenge of an increasingly aggressive tobacco industry, continued experimentation and initiation by youths, and the difficulty of achieving successful cessation among the millions of middle-aged and older adults at high risk for smoking-caused disease.

Here, I consider the implications for tobacco control in individual countries, such as Mexico, of happenings outside of their borders. In this time of globalization, the outcome of tobacco control in one country is inexorably tied to events at the global level. The tobacco industry has been consolidated into a small number of behemoth multinational corporations and, for example, Marlboro, by far the most widely smoked cigarette brand in Mexico, is also the world's most popular brand. ${ }^{3}$ Strategies for maintaining and expanding markets that are tested and found to be successful in one place can be quickly transferred to others by these companies. Tobacco control is also a global phenomenon; a global tobacco control community, linked through GLOBALink, antedated the FCTC, which had the consequence of creating even stronger networks. ${ }^{4}$ The World Conferences on Tobacco and Health, which began in 1967, have long been a critical venue for exchange at the global level. The tobacco control experts in Mexico have been part of this global community.

For the future, I identify several issues that are relevant for tobacco control in Mexico and other countries in this era of globalization of the tobacco industry and of tobacco control: the collective success of the ratifying nations in implementing the FCTC and the World Health Organization's MPOWER package in the face of industry tactics to limit success; ${ }^{5}$ the increasing diversity of products that deliver nicotine and their implications for initiation and cessation; the use of harm reduction strategies; and the regulation of tobacco products in the United States by the Family Smoking Prevention and Tobacco Control Act. ${ }^{6}$

\section{The global epidemic of tobacco use}

Casting the tobacco epidemic as a pandemic has become critical to its control. The tobacco industry is increasingly consolidated into a small number of multinational corporations, operating globally to expand their markets. While the China National Tobacco Corporation remains the largest manufacturer in the world, most tobacco manufacturing outside of China is carried out by a few companies: Philip Morris International, British American Tobacco, Japan Tobacco International, Imperial Tobacco, and several others. These companies have largely replaced prior national monopolies, and local, regional and national companies. The size and economic clout of these companies, along with aggressive marketing and promotion strategies, threatens public health throughout the world.

The epidemiological triangle, a construct long used for formulating approaches to infectious disease control, has proved equally applicable to the tobacco epidemic (figure 1). It offers a framework for considering how the tobacco industry advances its sales and how it can be controlled. The tobacco industry becomes the vector for spreading the epidemic-causing agent, the cigarette or other forms of tobacco products. The environment is multidimensional and includes the social environment (i.e., the social acceptability of smoking and its role in society), the policy and regulatory environment (e.g., smoking bans and the level of enforcement and restrictions on advertising), the financial environment (i.e., the costs of tobacco products, particularly in relation to household income), and the medical environment (e.g., emphasis on offering cessation and availability of cessation services). The product itself is also relevant to the tobacco pandemic, as we have learned that many
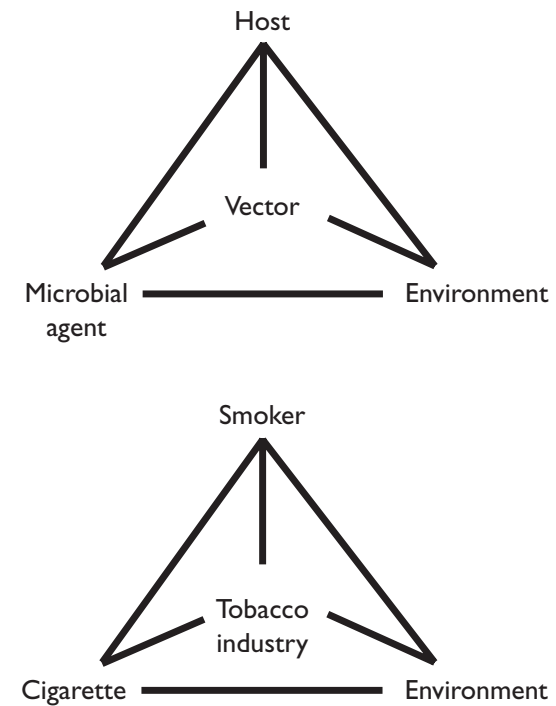

Figure I. The EPIDEMIOLOGIC tRIANGLE AND the tobacco EPIDEMIC 
aspects of the product may affect addiction liability and health risks. Mentholation of cigarettes, for example, has been found to increase likelihood of initiation by youths and to decrease successful cessation by established smokers. ${ }^{7}$ We have also learned that many individual characteristics, including genetic factors, may figure into risk for individuals to become smokers and to their risk for diseases caused by smoking.

However, the agent would not exist, absent the tobacco industry, and the industry is now globalized. As a global problem, a global solution is needed.

\section{The Framework Convention on Tobacco Control}

The FCTC provides a global response to the complex, international challenge of the tobacco epidemic. Its elements call for national and international actions that reflect the transboundary nature of the epidemic. In 1994, at the 9th World Conference on Tobacco or Health in Paris, Ruth Roemer, an academic and a tobacco control advocate from California, and Allyn Taylor, then a doctoral student from Columbia, drafted a resolution encouraging the development of a framework convention for tobacco control to respond to the increasingly trans-border nature of tobacco use. Only two years later in 1996, the World Health Assembly endorsed the idea of the FCTC and in 1998 the WHO Member States adopted, by consensus, a resolution leading toward accelerated multilateral negotiations on a framework convention on tobacco control and possible related protocols. The initiation of the FCTC process marked the first time that the Member States of WHO used the Organization's power under Article 19 of its constitution to negotiate and sign a binding treaty aimed at protecting and promoting public health.

The FCTC was developed as an evidence-based treaty through a working group process that was followed by formal negotiations. The WHO Member States unanimously adopted the final text of the FCTC in May, 2003. Many universal elements of national tobacco control policy became core provisions of the FCTC's final text (table I). The key provisions include a comprehensive ban on tobacco advertising, promotion and sponsorship (with an exception for countries, such as the United States, which deem it unconstitutional); a ban on misleading

Table I

\section{Key demand reduction provisions of the Framework Convention on Tobacco Control}

Article 6: Price and tax measures to reduce the demand for tobacco

Article 8: Protection from exposure to tobacco smoke

Article 9: Regulation of the contents of tobacco products

Article 10: Regulation of tobacco product disclosures

Article II: Packaging and labeling of tobacco products
Recognizes that price and tax measures are an effective and important means of reducing tobacco consumption, especially among young people

Requires parties to adopt and implement effective measures "providing for protection from exposure to tobacco smoke in indoor workplaces, public transport, indoor public places and, as appropriate, other public places."'

Obligates countries to require that manufactures and importers of tobacco products disclose to governmental authorities information about product contents and emissions. Measures for public disclosure must be adopted.

Conference of the Parties is to develop guidelines that can be used by countries for the testing, measuring and regulating contents and emissions. Parties must adopt pertinent measures at the national level.

Requires Parties to adopt and implement effective measures requiring large, clear health warnings, using rotating messages approved by a designated national authority. Provides that these warnings should cover $50 \%$ of more of the principle display areas and must occupy at least $30 \%$

Requires the Parties adopt and implement effective measures to ensure tobacco product packaging and labeling do not promote a tobacco product by any means that are false, misleading, deceptive or likely to create an erroneous impression about its characteristics, health effects, hazards or emissions.

Article 12: Education, communication, Requires the adoption of legislative, executive, administrative or other measures that promote public awareness and training and public awareness access to information on the addictiveness of tobacco, the health risks of tobacco use and exposure to smoke, the benefits of cessation and the actions of the tobacco industry.

Article 13: Tobacco advertising, pro- Requires, in accordance with constitutional limitations, a comprehensive ban on all tobacco advertising, promotion motion and sponsorship and sponsorship.

Article 14: Demand reduction measures concerning tobacco dependence and cessation

Requires creation of cessation programs in a range of settings, include diagnosis and treatment of nicotine dependence in national health programs, establish programs for diagnosis, and counseling and treatment in health care facilities and rehabilitation centers. 
descriptors intended to convince smokers that certain products are safer than "standard" cigarettes; and a mandate to place rotating warnings that cover at least $30 \%$ of tobacco packaging, with encouragement for even larger, graphic warnings. The FCTC also calls for countries to implement smoke-free workplace laws, address tobacco smuggling, increase tobacco taxes, and handle issues related to the supply side and the environment.

The FCTC entered into force in February 2005 after 40 countries had ratified the treaty. By the first Conference of Parties held in February 2006, 115 nations had ratified the treaty, including many of the treaty's strongest critics such as Japan, China, and Germany. To date, 174 nations are parties to the FCTC, although Indonesia, the United States, and Argentina have not ratified. The Conference of Parties has adopted guidelines for seven of the treaty Articles, including Article 8 which addresses secondhand smoke (SHS). Negotiations are also ongoing in regards to the treaty's first protocol - the Protocol on Illicit Trade of Tobacco Products.

The success of FCTC implementation is critical for global tobacco control; with the treaty in place for more than five years, the ratifying nations should be well into the process of implementing its provisions. Progress is variable across the parties, and opposed in various ways by the tobacco industry. Support for implementation comes from the well-timed Bloomberg Initiative to Reduce Tobacco Use, which is building capacity, offering grants, and supporting media, policy, and legal activities, the Bill and Melinda Gates Foundation, and several other funders. The World Health Organization (WHO) has developed and disseminated its MPOWER ( $\mathrm{M}=$ monitoring, $\mathrm{P}=$ protect, $\mathrm{O}=$ offer, $\mathrm{W}=$ warn, $\mathrm{E}=$ enforce, and $\mathrm{R}=$ raise taxes) package of tobacco control measures, which is complementary to the FCTC. The World Health Organization's Report on the Global Tobacco Epidemic shows that much remains to be achieved with each of these provisions globally (figure 2). ${ }^{8}$

Restating the obvious, the extent to which the parties implement the FCTC is critical to the success of global tobacco control. Absent effective control at the global level, the predictions are dire: a total of one billion premature deaths this century. The effectiveness of the FCTC has broader implications as it is considered a potential model for addressing the global rise of obesity, which is driven in part by the multinational food and beverage industries.

\section{The diversifying market for nicotine- delivering products}

In many high-income countries, the prevalence of smoking has dropped substantially. Factors driving the decline include broad understanding of the risks of smoking cigarettes, rising prices, the availability of ef-

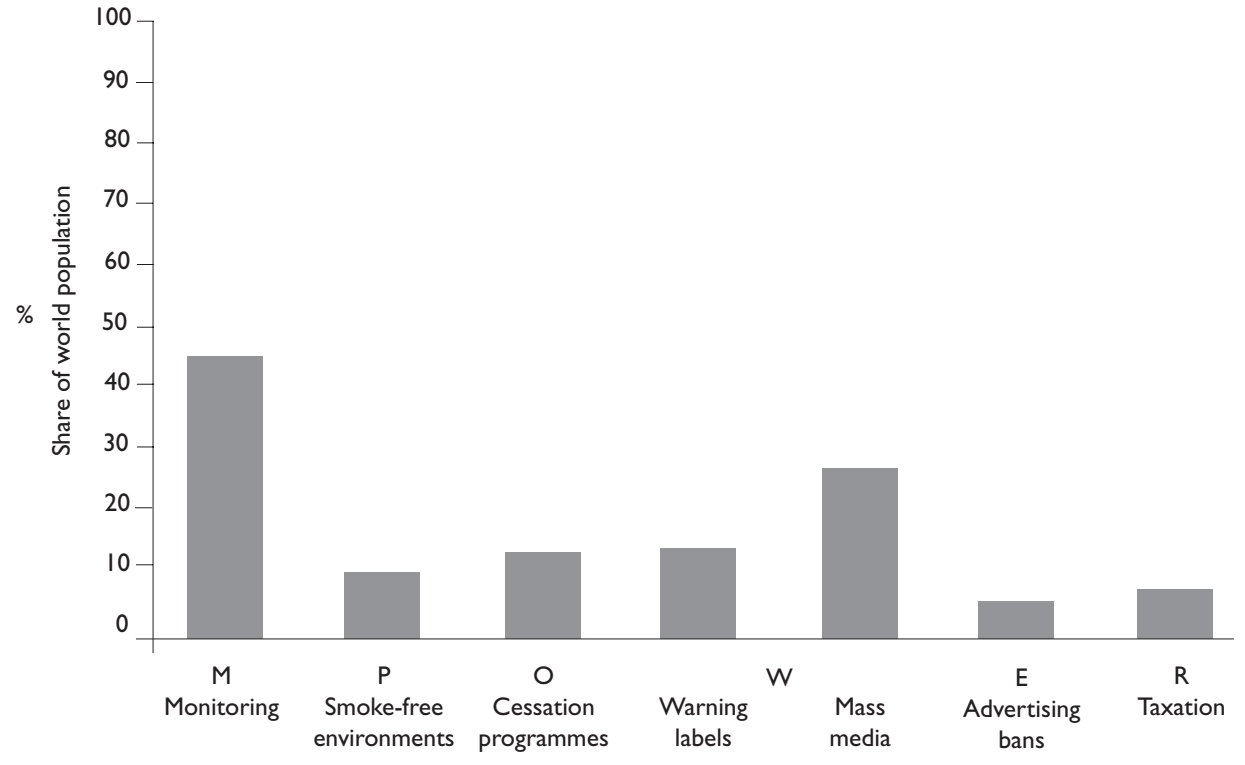

Note: Data correspond to the highest level of achievement at the national level, complete through 2010 Source: Reprinted from reference 8

Figure 2. Share of the global population covered by the World Health Organization's MpOWer package of TOBACCO CONTROL MEASURES 
fective cessation therapies, smoking bans, and changing societal views of smoking. Smoking bans and declining acceptability of smoking have made smoking more difficult for smokers, as the locations where they can smoke freely are now limited. In the United States, for example, most workplaces are covered by some form of ordinance and workplace SHS exposure is uncommon; additionally, the majority of homes with smokers have a policy about smoking within the home. ${ }^{10}$

In recent years, there is a widening array of noncombustible products that provide nicotine and that may be used in locations where smoking cigarettes is either not allowed or not acceptable. Snus, for example, is a moist snuff that has been widely used in Sweden, but with little distribution elsewhere until recently. Now, each of the major companies is marketing snus in the United States with marketing slogans indicating that the product can be used anywhere and at all times. Electronic cigarettes (e-cigarettes) have entered the global market in the last few years. These devices, first made in China, produce a nicotine-containing vapor through a heating element. Dissolvable products (e.g., Camel Sticks, Orbs, and Strips) have been developed and are currently being test-marketed.

To date, there is limited experience with most of these products, except snus which has long been used in Sweden. Whether they will reduce quit attempts and the rate of successful cessation is uncertain. If they prove successful from the industry perspective, their use may be promoted by the industry and made global, potentially hindering tobacco control at the global level.

\section{Harm reduction strategies}

Tobacco control strategies for reducing the enormous burden of avoidable disease from smoking have long given emphasis to prevention of initiation and enhancement of quitting. Development of less hazardous products, whether smoked or not smoked, represents another strategy, so-called "harm reduction," for limiting the burden of smoking-caused morbidity and premature mortality. The topic of harm reduction in regard to tobacco use has been contentious, although harm reduction strategies are in use for other addictions, e.g., needle exchange programs for addicted users of intravenous drugs. ${ }^{11}$ Views on using harm reduction strategies for smoking have been colored by the industry's decadeslong strategy of marketing some products as lower risk, beginning with the addition of filters to most cigarettes and then the use of misleading descriptors, such as "light" or "mild", for products with lower yields of tar and nicotine, as measured by a machine. Such claims were found to be fraudulent in Judge Kessler's decision in the litigation against the tobacco industry brought by the United States Department of Justice. ${ }^{12}$

Harm reduction strategies involve the use of tobacco or nicotine-delivering products that have the potential to reduce exposure to injurious components of tobacco smoke; such products have been labeled as PREPs, potential reduced-exposure products. ${ }^{13} \mathrm{~A}$ variety of products have been proposed as PREPs, including smokeless tobacco products and e-cigarettes. For such products, there is a potential for risks to individuals to be reduced but for the overall public health impact to be adverse. A product might reduce risk for smokingcaused disease by reducing the number of cigarettes smoked but have an overall adverse impact on public health by reducing the rate of successful cessation and increasing the rate of initiation. In the United States, the new Family Smoking Prevention and Tobacco Control Act requires that a modified risk product be marketed only if: "...the Secretary determines that the applicant has demonstrated that such product, as it is actually used by consumers, will- “(A) significantly reduce harm and the risk of tobacco related disease to individual tobacco users; and "(B) benefit the health of the population as a whole taking into account both users of tobacco products and persons who do not currently use tobacco products."

There will likely be a number of products marketed as useful for harm reduction. The increasing numbers of products being manufactured is indicative. The twopronged test required in the US legislation needs to be considered at the global level as harm reduction strategies are introduced. Undoubtedly, the debate about the role of harm reduction in tobacco control will be ongoing and remain contentious.

\section{Regulation of tobacco products}

In 2009, the United States passed the Family Smoking Prevention and Tobacco Control Act ("the Act"), giving the Food and Drug Administration (FDA) authority to regulate certain tobacco products with the goal of protecting public health. The Act's broad provisions provide FDA a set of regulatory tools for reducing harm to health from products that cause nicotine addiction and disease (table II). To date, the FDA has developed the structure and staff needed to fulfill its mandate, creating the Center for Tobacco Products. Its Tobacco Products Scientific Advisory Committee has completed a report on the public health impact of menthol in cigarettes, finding that the inclusion of menthol as a cigarette additive harms the public health. The FDA has also identified a list of hazardous components of tobacco smoke, a listing also carried out by the WHO. ${ }^{14}$ 


\section{Table II}

\section{Purposes of the Family Smoking Prevention and Tobacco Control Act}

(I) to provide authority to the Food and Drug Administration to regulate tobacco products under the Federal Food, Drug, and Cosmetic Act (2I U.S.C. 30I et seq.), by recognizing it as the primary Federal regulatory authority with respect to the manufacture, marketing, and distribution of tobacco products as provided for in this division;

(2) to ensure that the Food and Drug Administration has the authority to address issues of particular concern to public health officials, especially the use of tobacco by young people and dependence on tobacco; H. R. 1256-7

(3) to authorize the Food and Drug Administration to set national standards controlling the manufacture of tobacco products and the identity, public disclosure, and amount of ingredients used in such products;

(4) to provide new and flexible enforcement authority to ensure that there is effective oversight of the tobacco industry's efforts to develop, introduce, and promote less harmful tobacco products:

(5) to vest the Food and Drug Administration with the authority to regulate the levels of tar, nicotine, and other harmful components of tobacco products;

(6) in order to ensure that consumers are better informed, to require tobacco product manufacturers to disclose research which has not previously been made available, as well as research generated in the future, relating to the health and dependency effects or safety of tobacco products;

(7) to continue to permit the sale of tobacco products to adults in conjunction with measures to ensure that they are not sold or accessible to underage purchasers;

(8) to impose appropriate regulatory controls on the tobacco industry;

(9) to promote cessation to reduce disease risk and the social costs associated with tobacco-related diseases; and

(I0) to strengthen legislation against illicit trade in tobacco products.

The Act is the first effort to regulate tobacco products. Determinations made under the Act may have consequences that extend outside the United States, particularly if precedent setting. Additionally, the new FDA center will likely elaborate product testing protocols with broad applicability.

\section{Conclusions}

Over the last decade, tobacco control has become an increasingly consolidated global movement, catalyzed by the FCTC and the Bloomberg Initiative. This global movement represents a needed response to the consolidation of the tobacco industry into a small group of multinational companies. Success of tobacco control in particular countries depends, in part, on the success of the global collective. Looming issues for tobacco control include the success with which the FCTC is implemented, finding the proper role of harm reduction approaches, and using "lessons learned" from experience in the United States with product regulation.

Declaration of conflict of interests: The author declare that they have no conflict of interests.

\section{References}

I. World Health Organization. WHO Framework Convention on Tobacco Control (FCTC). Geneva: WHO, 2003.
2. Pan American Health Organization, Instituto Nacional de Salud Pública. Global Adult Tobacco Survey Mexico 2009 (GATS). Cuernavaca, Mexico: INSP, 2010.

3. Shafey O, Eriksen M, Ross H, Mackay J. The Tobacco Atlas, 3rd edition. Atlanta: American Cancer Society, 2009.

4. Wipfli HL, Fujimoto K, Valente TW. Global Tobacco Control Diffusion: The Case of the Framework Convention on Tobacco Control. Am J Public Health 2010;100(7):1260-1266.

5. World Health Organization. WHO report on the global tobacco epidemic, 2008: the MPOWER package. Geneva: WHO, 2008. 6. H.R. 1256 [I I Ith]: Family Smoking Prevention and Tobacco Control Act, Pub. L. No. II I-3I, I 23 Stat. 1776 (June 22, 2009).

7. U.S. Food and Drug Administration, Tobacco Products Scientific Advisory Committee (TPSAC). Menthol cigarettes and public health: review of the scientific evidence and recommendations. Rockville, MD: U.S. Food and Drug Administration, Center for Tobacco Products, $201 \mathrm{I}$. 8. World Health Organization. WHO report on the global tobacco epidemic, 20II: Warning about the dangers of tobacco. Geneva: WHO, 20II.

9. Wipfli H, Samet JM. Global economic and health benefits of tobacco control: part 2. Clin Pharmacol Ther 2009;86(3):272-280.

I0. U.S. Department of Health and Human Services. The health consequences of involuntary exposure to tobacco smoke. A report of the Surgeon General. Atlanta, GA: U.S. Department of Health and Human Services, Centers for Disease Control and Prevention, Coordinating Center for Health Promotion, National Center for Chronic Disease Prevention and Health Promotion, Office on Smoking and Health, 2006. II. Zeller M, Hatsukami D. The Strategic Dialogue on Tobacco Harm Reduction: a vision and blueprint for action in the US. Tob Control 2009; I8(4):324-332.

12. United States of America vs. Philip Morris USA, Inc., etc. United States District Court for the District of Columbia; 2006. I3. Stratton K, Shetty P, Wallace R, Bondurant S, eds. Clearing the smoke: assessing the science base for tobacco harm reduction. Washington, DC: National Academy Press, 200I.

14. World Health Organization. The scientific basis of tobacco product regulation: second report of a WHO study group. Geneva: WHO, 2008. 